\title{
Fabrication of an Immunosensor for Cardiac Troponin I Determination
}

\author{
Yaowen $\mathrm{Xu}^{1}$, Shufang Yang ${ }^{2}$ and Wei Shi, \\ ${ }^{1}$ Department of Cardiology, Daqing Longnan Hospital, Daqing City, Heilongjiang Province, 163453, \\ P.R. China \\ ${ }^{2}$ The Emergency Department of the Second People's Hospital, Liaocheng, Linqing City, Shandong \\ Province, 252600, P.R. China \\ ${ }^{3}$ ECG Room, Shangluo Central Hospital, Shangluo City, Shaanxi Province, 726000, P.R. China \\ *E-mail: shiwei_William@foxmail.com
}

doi: $10.20964 / 2017.09 .65$

Received: 26 May 2017 / Accepted: 23 July 2017 / Published: 13 August 2017

\begin{abstract}
Using the stripping voltammetry of platinum or palladium nanoparticles as the basis, this work proposes an emerging electrochemical technique to detect cardiac troponin I (cTnI). The amount of cTnI specifically adsorbed on an anti-cTnI-modified electrode surface was related to the PdNP (Pd) and PtNP (Pt) current responses. Plasma specimens from acute myocardial infarction (AMI) sufferers and healthy donors were used for cTnI surveillance. SPE/PdNP/anti-cTnI exhibits a wide detection range of $0.1-40 \mathrm{ng} / \mathrm{ml}$, with a low detection limit (DL) of $0.1 \mathrm{ng} / \mathrm{ml}$. SPE/PtNP/anti-cTnI exhibits a wide detection range of $0.1-55 \mathrm{ng} / \mathrm{ml}$, with a low detection limit (DL) of $0.07 \mathrm{ng} / \mathrm{ml}$.
\end{abstract}

Keywords: Cardiovascular diseases; Immunosensor; Cardiac troponin I; Platinum; Palladium

\section{$\underline{\text { FULL TEXT }}$}

(C) 2017 The Authors. Published by ESG (www.electrochemsci.org). This article is an open access article distributed under the terms and conditions of the Creative Commons Attribution license (http://creativecommons.org/licenses/by/4.0/). 